\title{
MUDANÇAS INSTITUCIONAIS E SUAS CONSEQUÊNCIAS: uma análise do sistema de comissões brasileiro ${ }^{1}$
}

\section{INSTITUTIONAL CHANGES AND THEIR CONSEQUENCES: an analysis of the brazilian committee system}

\author{
Vitor Vasquez* \\ Géssica de Freitas**
}

\section{Resumo}

As comissões brasileiras eram tidas como instituições pouco relevantes. Contudo, recentemente, passaram a ser interpretadas como lócus de análise e alteração de projetos. Esta reavaliação, no entanto, não esclareceu se, ao longo do tempo, houve momentos de mais ou menos protagonismo das comissões, tampouco se isto foi resultado de transformações promovidas por partidos e deputados. Este artigo visa preencher essa lacuna, ao identificar e analisar as consequências de 27 mudanças institucionais (19892018), a partir de Projetos de Resolução que alteraram o Regimento Interno da Câmara dos Deputados. Investigamos essas proposições, considerando quatro tipos de alteração: denominação, quantidade de comissões, número de membros e organização interna dos trabalhos. Nossos resultados demonstram que as mudanças institucionais aumentaram o número de comissões e buscaram aprimorar seus procedimentos internos, visando ampliar o grau de especialização do sistema, expandir sua participação no processo legislativo e tornar mais eficiente as atividades desenvolvidas no seu interior.

Palavras-chave: Comissões Temáticas; Câmara dos Deputados; Mudança Institucional.

\begin{abstract}
Brazilian committees were regarded as unimportant institutions. However, recently, they have been interpreted as locus of project's analysis and modification. This reevaluation, on the other side, did not clarify whether, over time, there were periods of more or less relevance of the committees, nor whether if this was consequence of transformations promoted by parties and deputies. This article aims to fill this gap by identifying and analyzing the consequences of 27 institutional changes (1989-2018), based on draft resolutions that modified the Rules of the House of Representatives. We investigated these propositions considering four types of change: denomination, number of committees, number of members, and internal organization of work. Our results show that institutional changes increased the number of committees and sought to improve their

\footnotetext{
${ }^{1}$ As opiniões, hipóteses e conclusões ou recomendações expressas neste material são de responsabilidade dos autores e não, necessariamente, refletem a visão da FAPESP.

* Doutorando em Ciência Política (DCP/IFCH/Unicamp/Brasil). Bolsa Fapesp: projeto n ${ }^{\circ}$ 2016/10421-1. Bolsa Fapesp Estágio de Pesquisa no Exterior (UCSD): projeto no 2018/00013-9. E-mail: vitor.vasquez@gmail.com.

** Graduanda em Ciências Sociais (Unicamp/Brasil). Bolsa Fapesp: Projeto no 2019/01847-3. E-mail: gessicafreitas.mm@gmail.com.
} 
internal procedures, aiming to increase the system's degree of specialization, expand its participation in the legislative process and make its activities more efficient.

Keywords: Committees; House of Representatives; Institutional Change.

\section{Introdução}

O atual sistema de comissões brasileiro foi estabelecido pela Constituição Federal de 1988 (CF-88). Desde então, tem suas características definidas via Regimento Interno da Câmara dos Deputados (RICD). Essencialmente, o sistema é composto por comissões permanentes que, cada qual em sua competência, examinam os projetos de lei que tramitam pelo Legislativo. No entanto, a forma como este sistema se organiza para exercer tal função modifica-se com alguma frequência. Isto pode ser observado pelo crescente número de comissões permanentes, por alterações na quantidade de deputados nomeados para cada comissão e pela inclusão, supressão ou desagregação de temáticas incluídas numa mesma comissão.

A análise de mudanças institucionais tem demonstrado o quanto compreender as regras - formais e informais - e suas alterações auxiliam na compreensão de processos políticos e seus resultados (BINDER, 1995; GOMES, 2006; IMMERGUT, 1992; MEDEIROS, 2013; NORTH, 1990; PRZEWORSKI, 2004). Afinal, em uma democracia, uma instituição política é alterada pelos próprios atores que a permeiam (NORTH, 1990) e por sua maioria (KREHBIEL, 1992). Assim, tal processo tende a representar a preferência média de quem atua sob a égide da instituição modificada.

O objetivo deste artigo é identificar as alterações institucionais ocorridas no sistema de comissões brasileiro entre 1989 e 2018, bem como analisar as consequências destas modificações na estrutura e no funcionamento destes órgãos. Esta estratégia nos possibilita avaliar se o Poder Legislativo considera as comissões lócus relevantes, ou não, de tomada de decisão, e em que medida atua, ao longo do tempo, para fortalecer ou enfraquecê-las. Dado que as modificações consideradas são propostas e levadas a cabo pela própria Câmara, via RICD, estas conformam um indicativo preciso da interpretação dos atores políticos que atuam nas comissões sobre o sistema do qual participam. Consequentemente, ao cumprir nosso objetivo, fornecemos um desenho acurado de como 
o sistema de comissões brasileiro se moldou e atingiu o atual estado de funcionamento. Assim, buscamos, a partir de um estudo exploratório, analisar as intenções e consequências destas alterações, para mapearmos este cenário e construirmos hipóteses a partir dos resultados encontrados.

Para executar nosso propósito, investigamos as mudanças institucionais sofridas pelo sistema de comissões que ocorreram através dos Projetos de Resolução da Câmara dos Deputados (PRC) e que se transformaram em norma jurídica durante o recorte temporal estabelecido. Isto foi feito considerando quatro características: denominação das comissões, quantidade de comissões, número de membros titulares e organização interna dos trabalhos. Tais aspectos, em especial os três últimos, são destacados pela literatura como indicadores do grau de relevância das comissões no processo legislativo. Nesse sentido, indicam quanto o sistema incentiva a participação em suas comissões e o grau de expertise na competência pela qual cada órgão é responsável (MARTIN; VANBERG, 2013; MARTIN, 2014; MATTSON; STRØM, 1995; STRØM, 1990).

Nossos principais resultados demonstram que as mudanças institucionais analisadas aumentaram o número de comissões do sistema ao longo dos anos. Isto sugere um ganho de especialização a partir da individualização de certas temáticas que outrora compartilhavam o mesmo órgão, e de uma atualização do sistema, ao incorporar novas competências. Além disso, demonstramos uma preocupação dos partidos e deputados em aprimorar procedimentos, visando ampliar os poderes da comissão enquanto órgão coletivo e solucionar possíveis problemas de trâmite de projetos, em casos de omissão dos relatores. Em outras palavras, as alterações promovidas no interior da Câmara buscaram aumentar o grau de especialização do sistema de comissões, ampliar sua participação no processo legislativo e tornar mais eficiente as atividades desenvolvidas no seu interior. Isso denota uma contínua preocupação de partidos e deputados em aprimorar e fortalecer as comissões permanentes.

$\mathrm{O}$ artigo conta com mais quatro seções, além desta. Na seguinte, apresentamos brevemente o debate acerca do sistema de comissões brasileiro, e sobre como a análise de mudanças institucionais pode colaborar nesta discussão. Isto feito, definimos nosso universo de análise e expomos as estratégias mobilizadas para classificar suas unidades. 
Em seguida, analisamos os resultados obtidos. Por fim, realizamos algumas considerações, com foco nos ganhos e limites apresentados por nosso artigo, destacando algumas frentes de pesquisa que se abrem a partir deste estudo.

\section{Mudanças Institucionais e Sistema de Comissões}

Há duas décadas, a literatura acerca do processo legislativo brasileiro o tinha como um espaço de produção legal centralizado pelo Executivo e Colégio de Líderes² ${ }^{2}$ sendo, portanto, determinado por fatores exógenos às comissões temáticas. Neste entendimento, a melhor expressão da pouca importância do sistema de comissões seria sua baixa autonomia, causada pela possibilidade do pedido de urgência. Segundo Figueiredo e Limongi (2001), o Legislativo teria o rito ordinário das matérias frequentemente interrompido pela urgência, que retira os projetos de lei das comissões com ou sem apreciação da mesma. Ou seja, ainda que as comissões possuam prerrogativas regimentais, quando o Executivo ou o Colégio de Líderes utiliza a urgência, essas são inibidas de utilizá-las. Ao mesmo tempo, as matérias que seguem a rota ordinária de tramitação possuem baixa probabilidade de se tornarem leis (FIGUEIREDO; LIMONGI, 2001, p. 3).

Pesquisas recentes, contudo, passaram a analisar o papel das comissões sob uma nova perspectiva (FREITAS, 2016; SANTOS; ALMEIDA, 2011). Primeiramente, Santos e Almeida (2011) afirmaram que a maioria dos pedidos de urgência são aprovados com consenso, ou seja, com ao menos $95 \%$ dos votos favoráveis. Segundo os autores, isso significaria que os partidos entram em consenso, através do colégio de líderes, sobre a urgência para acelerar a aprovação do projeto já discutido, e sobre o qual já se atingiu um acordo em relação ao conteúdo substantivo dos mesmos (SANTOS; ALMEIDA, 2011, p. 52-53). Desse modo, ainda que o procedimento da urgência tenha papel proeminente no Legislativo brasileiro, por ser aprovado consensualmente, todos os partidos, inclusive os da oposição, concordam com o teor da matéria, alvo deste procedimento.

Freitas (2016), por outro lado, entende que as comissões temáticas são importantes para o processo decisório, uma vez que o número de alterações que estes órgãos realizam

\footnotetext{
${ }^{2}$ Grupo formado pelos líderes dos partidos, o presidente da Câmara, líderes da maioria, da minoria e dos blocos parlamentares.
} 
nos projetos do Executivo é significativo. Mais, isto ocorre mesmo em projetos com tempo reduzido de tramitação, como Medidas Provisórias (MPV), ou projetos com pedido de urgência. Estas alterações são realizadas pelos relatores, atores responsáveis por escrutinizar as matérias submetidas às comissões. Através destas modificações, o Legislativo adiciona, suprime e/ou, modifica conteúdos do projeto original. Portanto, a urgência não retiraria poder das comissões do Legislativo, pois $45 \%$ dos projetos foram deliberados no interior destas, mesmo com o pedido de urgência realizado (FREITAS, 2016, p. 78). Em suma, é possível inferir que as comissões são lócus privilegiado de deliberação dos projetos, e desconsiderar suas atuações no processo legislativo impossibilita uma visão mais completa do sistema político brasileiro.

No entanto, ainda que estes trabalhos lancem luz à relevância do sistema de comissões no Brasil, não esclarecem em que medida esta atuação variou ao longo do tempo. Ou seja, não esclarecem se houve momentos de mais ou menos protagonismo das comissões na produção legal, e em que medida as variações foram resultado das frequentes modificações que elas sofreram ao longo dos anos. Isto configura uma lacuna nos estudos legislativos brasileiros que, para ser preenchida, demanda uma análise das mudanças institucionais sofridas pelo sistema de comissões, desde a sua criação.

Mudanças institucionais alteram as regras do jogo que conformam as estratégias disponíveis aos atores políticos. Assim, influenciam a elaboração e o resultado de políticas públicas, sendo, portanto, essenciais para a compreensão do processo legislativo. As alterações nas normas que regem o sistema político são feitas pelos próprios políticos, isto é, são endógenas (NORTH, 1990). Ao mesmo tempo, conforme destaca Krehbiel (1992), mudanças institucionais só permanecem ou ocorrem enquanto houver uma maioria para sustentá-las ou encampá-las. Dado que os próprios políticos promovem as mudanças institucionais e o imperativo majoritário pelo qual estas são elaboradas e implementadas, as regras do processo legislativo tendem a refletir a preferência média da maioria. Por isso, quando a maioria não está satisfeita com os resultados promovidos pelas instituições, se organiza para alterá-las.

Immergut (1992) compara três países para demonstrar como distintas normas institucionais podem levar a lógicas variadas de tomada de decisão, interferindo nos 
VASQUEZ, Vitor; FREITAS, Géssica de. Mudanças institucionais e suas consequências: uma análise do sistema de comissões brasileiro. Caos - Revista Eletrônica de Ciências Sociais, João Pessoa, n. 23, p 36-55, jul./dez. 2019. Disponível em: https://periodicos.ufpb.br/ojs2/index.php/caos/index.

parâmetros da ação de governo e da influência de grupos de interesses. Através de uma análise da dinâmica institucional da tomada de decisão política, a autora demonstra como diferentes regras constitucionais, resultados eleitorais e regimentos internos tendem a influenciar no processo decisório e, assim, resultar em políticas públicas com efeitos distintos umas das outras.

De forma análoga, Gomes (2006) demonstra que o resultado final da Constituição de 1988 (CF-88) foi influenciado pelo conjunto de regras e procedimentos definidos e alterados durante a Assembleia Nacional Constituinte (ANC). Conforme destaca, as "normas ou regras estabelecidas tendem também a influenciar o comportamento e, portanto, as escolhas dos parlamentares" (GOMES, 2006, p. 195). De acordo com a autora, o estabelecimento de dois regimentos internos distintos, no processo de produção legislativa, modificou radicalmente o rumo para o qual se caminhava a CF-88. Desse modo, argumenta, a alteração do regimento foi promovida por um novo bloco, formado para conter o andamento dos trabalhos, que se autodenominava Centrão, ratificando o papel fundamental da maioria em mudanças institucionais.

Medeiros (2013) também explora mudanças institucionais na Constituinte, ao buscar demonstrar que as normas que regularam a organização de trabalho na Assembleia Nacional Constituinte (ANC) interferiram no resultado final das propostas elaboradas em seu interior. Conforme pontua, se as regras de um processo não influenciassem seu resultado, uma maioria de parlamentares descontente com os rumos dos trabalhos constituintes não teria solicitado uma reformulação do Regimento Interno quase um ano após o estabelecimento da ANC. Para o autor, o substitutivo que alterou o Regimento Interno, em dezembro de 1987 - aprovado com 290 votos favoráveis e 16 contrários - era uma prova de que quando uma regra não agrada a maioria, ela muda a regra. Ainda, quando os atores mudam as regras eles estão, de fato, visando alterar os resultados produzidos pelas instituições que passaram a ser regidas de maneira distinta.

A partir disto, é possível inferir que as sucessivas modificações sofridas pelas comissões possuem intencionalidades e consequências. Isto sugere uma preocupação sistemática dos parlamentares em relação a estes órgãos, pois uma maioria deles aprova, frequentemente, Projetos de Resolução da Câmara dos Deputados (PRC) que, desde 1989, 
VASQUEZ, Vitor; FREITAS, Géssica de. Mudanças institucionais e suas consequências: uma análise do sistema de comissões brasileiro. Caos - Revista Eletrônica de Ciências Sociais, João Pessoa, n. 23, p 36-55, jul./dez. 2019. Disponível em: https://periodicos.ufpb.br/ojs2/index.php/caos/index.

alteram as comissões em diferentes aspectos. Entre 1989 e 2018, 27 resoluções modificaram o sistema de comissões, seja alterando as regras de funcionamento, seja criando, fundindo, desmembrando e/ou, extinguindo comissões temáticas da Câmara dos Deputados. Estas resoluções, propostas e ratificadas pela Casa, indicam que o próprio Legislativo buscou modelar o sistema de comissões com o passar do tempo. Por um lado, tais mudanças institucionais podem ter fortalecido ou enfraquecido o sistema de comissões como um todo, do ponto de vista da participação no processo legislativo. Por outro, podem atuar como incentivos ou obstáculos à dedicação de um ou mais ator político às comissões. Para tanto, os partidos e seus deputados devem transformar aspectos estruturais das comissões e/ou sua dinâmica interna de trabalho.

Diversos fatores estruturais são apontados pela literatura como relevantes para um funcionamento eficiente do sistema de comissões (MARTIN; VANBERG, 2013; MARTIN, 2014; MATTSON; STRØM, 1995; STRØM, 1990). Dentre esses aspectos, destacamos o total de comissões que compõem o sistema e o número de membros que integra cada comissão. Além disso, a forma pela qual as comissões organizam seus trabalhos, seus procedimentos e suas prerrogativas e limites também podem tornar o sistema mais ou menos habilitado às tomadas de decisões. ${ }^{3}$

A quantidade de comissões é um indicativo de grau de especialização política destes órgãos. Afinal, um número baixo de comissões sugere que poucas jurisdições são abarcadas pelo sistema, ou que uma ou mais comissões são responsáveis por mais de uma temática. Ambas situações configuram potenciais déficits de especialização para um sistema que deve ser o mais preparado possível para escrutinizar os projetos que apreciam. Por exemplo, uma comissão responsável por deliberar apenas sobre questões de educação, sem precisar ao mesmo tempo se ocupar de questões de cultura, contará com mais tempo, espaço e oportunidade para melhor informar-se acerca da primeira temática. Isso significa que um aumento no número de comissões tende a ampliar a capacidade

\footnotetext{
${ }^{3}$ Quatro tipos de poder têm sido destacados como importantes características procedimentais para um sistema de comissões potencialmente forte (MARTIN; VANBERG, 2013; MARTIN, 2014): (1) de apreciar as propostas legislativas antes de passarem pelo plenário, (2) de indicar a aceitação total ou parcial das propostas, bem como de alterá-las, (3) de solicitar que qualquer cidadão ou autoridade testemunhe nas comissões, incluindo ministros, e (4) de não ter o trabalho interno interrompido por procedimento de urgência.
} 
VASQUEZ, Vitor; FREITAS, Géssica de. Mudanças institucionais e suas consequências: uma análise do sistema de comissões brasileiro. Caos - Revista Eletrônica de Ciências Sociais, João Pessoa, n. 23, p 36-55, jul./dez. 2019. Disponível em: https://periodicos.ufpb.br/ojs2/index.php/caos/index.

administrativa e informacional do sistema, aumentando seu grau de especialização. $\mathrm{O}$ total de comissões de um sistema é alterado quando, via aprovação de PRC, o plenário sugere a criação, extinção, fusão ou desmembramento de jurisdições. Por isso, este aspecto se relaciona também ao tempo de existência de cada comissão. Não por acaso, a idade da comissão também tende a ser um indicativo do seu grau de especialização. Afinal, quanto mais antiga for, maior tende a ser sua expertise na temática pela qual é responsável. ${ }^{4}$

Quanto ao total de membros que compõe as comissões, esta é uma característica que pode impactar no processo de tomada de decisão. Martin e Vanberg (2013) apontam que comissões muito numerosas podem gerar problemas de coordenação. Ao mesmo tempo, a presença de muitos membros tende a incentivar que políticos atuem como freeriders, desencorajando que estes se especializam na jurisdição a qual pertencem. Para evitar que muitos ou poucos membros participem da mesma comissão, pode-se limitar, institucionalmente, o total de membros recrutados para cada um destes órgãos (STRØM, 1990, p. 71). Quando isto ocorre, ou seja, quando há um controle regimental de número máximo e mínimo de participantes por comissão, o número de membros titulares de uma pode representar em que medida os atores políticos se interessam pela jurisdição do órgão. ${ }^{5}$ Nesse caso, a relação é direta: quanto mais integrantes tiver, maior tende a ser o interesse dos partidos e seus deputados em atuar nessa comissão.

Por fim, modificações na organização interna do trabalho das comissões podem fortalecer ou enfraquecer estes órgãos. Uma alteração que retira poder de agenda das comissões tende a gerar obstáculos para que deputados dediquem seu tempo a estas. Analogamente, alterações que ampliem o poder das comissões, e que as tornem mais eficientes, tendem a incentivar a participação de partidos e deputados, bem como a especialização destes atores nas temáticas em que atuam.

Para além desses três critérios, incluímos uma quarta classificação, a de denominação. Após a análise das ementas dos PRCs, observamos que parcela relevante

\footnotetext{
${ }^{4}$ Huber e Martinez-Gallardo (2008) utilizam o tempo de existência dos ministérios como uma medida de seu grau de institucionalização e, consequentemente, de importância. Para nós, a mesma lógica pode se estender às comissões e outras instituições políticas.

${ }^{5}$ No Brasil, o RICD determina um mínimo de 3,5\% da Câmara dos Deputados e um máximo de $13 \%$ como limites de membros de cada comissão.
} 
versava, exclusivamente ou não, sobre a alteração de denominação das comissões, nos chamando atenção para a importância de analisar também esse tipo de modificação. A partir disso, nos utilizaremos desses aspectos estruturais como categorias para classificar as 27 resoluções que modificaram o sistema de comissões.

\section{Identificando e Classificando as Mudanças Institucionais}

Nosso universo de análise é composto por todas mudanças institucionais, incluídas no RICD, que alteraram o sistema de comissões. Para identificar quais PRCs promoveram as modificações, analisamos todos os RICDs de 1989 a 2018, comparando sempre o mais recente com o do ano anterior. Listadas as alterações observadas nos regimentos, separamos aquelas que se referiam diretamente às comissões temáticas ou que afetariam em alguma medida seu funcionamento. Utilizando este método, encontramos 20 PRCs de nosso interesse, que foram transformados em norma jurídica.

A fim de aprimorar nossa investigação, bem como fazer uma segunda conferência na seleção anterior, utilizamos outro rastreamento de alterações. Desta vez, mobilizamos a ferramenta de busca avançada de propostas legislativas na página eletrônica da Câmara dos Deputados. ${ }^{6}$ Nesta etapa, utilizamos os seguintes filtros de busca: PRCs, de 01/01/1989 a 31/12/2018, transformados em norma jurídica. A busca nos retornou 323 projetos cujas ementas analisamos uma a uma para estabelecer uma hierarquização de relevância para nossa pesquisa.

Foram classificados como 0 , os PRCs que não impactaram o sistema de comissões. Esta categoria incluiu homenagens, premiações, criação de grupos parlamentares, projetos que versam sobre perda de mandato etc. Por outro lado, os projetos classificados como 1 não se referem diretamente ao sistema de comissões, mas indiretamente podem influenciá-lo. Neste grupo enquadram-se modificações no RICD como funcionamento do plenário, sessões, votações e afins. Por fim, os projetos classificados como 2 foram aqueles que influenciaram diretamente o sistema de comissões. A ferramenta de busca retornou 27 projetos que se enquadram nesta classificação. Para os objetivos deste artigo, analisamos somente os projetos classificados

\footnotetext{
${ }^{6}$ https://www.camara.leg.br/buscaProposicoesWeb/pesquisaAvancada. Acesso em: 31//07/2019.
} 
como 2. Essa segunda verificação ratificou as 20 alterações identificadas anteriormente e acrescentou sete PRCs aos dados encontrados preliminarmente.

Isto feito, investigamos os conteúdos dessas resoluções, observando possíveis padrões nas mudanças que propõem. Precisamente, utilizamos quatro critérios de modificação: (1) denominação - altera o nome de uma ou mais comissão; (2) composição - restringe ou amplia o número de membros de uma ou mais comissão; (3) número de comissões - modifica o total de comissões do sistema através de criação, fusão, desmembramento ou extinção de jurisdição; e (4) procedimento - transforma a organização interna dos trabalhos nas comissões. Dentre os 27 PRCs encontradas, 12 discorrem sobre composição das comissões, quatro alteram denominação, 15 versam sobre criação, extinção, desmembramento ou fusão de competência e cinco modificam a dinâmica de tramitação. Algumas resoluções tratam de mais de um assunto ao mesmo tempo e, portanto, foram inseridas em mais de uma classificação. A organização dos projetos segundo nossos critérios de modificação encontra-se na tabela 1.

Tabela 1: Classificação dos PRCs que alteram o sistema de comissões, 1989 a 2018

\begin{tabular}{ccc}
\hline Categoria de Alteração & PRC & Total \\
\hline Denominação & $196 / 1994,118 / 2003,173 / 2013 \mathrm{e}$ & 4 \\
& $541 / 2014$. & \\
Composição & $27 / 1999,118 / 2003,200 / 2005,201 / 2005$, & 12 \\
& $20 / 2011,115 / 2012,168 / 2013$ e 134/2016. & \\
& $54 / 1989,55 / 1989,57 / 1991,101 / 1992$, & \\
Número de Comissões & $229 / 1994,21 / 1995,231 / 1995,27 / 1999$, & 15 \\
& $151 / 2001,5 / 2003,118 / 2003,8 / 2007$, & \\
& $20 / 2011,166 / 2013$ e 237/2014. & \\
Procedimento & $54 / 1989,55 / 1989,59 / 1991,200 / 1994$ e & 5 \\
& $134 / 2016$. & \\
\hline
\end{tabular}

Fonte: Elaboração própria 
De acordo com os dados da tabela 1, a maior parte dos PRCs modificou aspectos estruturais, isto é, composição e número de comissões do sistema. Chama atenção que a maioria das alterações procedimentais foi feita no começo do atual sistema, até a primeira metade dos anos 1990. Por outro lado, as modificações estruturais, além de ocorrerem com maior frequência, são distribuídas mais homogeneamente ao longo do tempo. Na próxima seção apresentamos nossos resultados, analisando detalhadamente como estes projetos aprovados impactaram o sistema de comissões no Brasil.

\section{Analisando as Mudanças Institucionais}

A primeira categoria de alteração analisada diz respeito aos PRCs que modificaram a denominação de alguma comissão. Esse tipo de alteração, geralmente, se sustenta por dois tipos de justificativa. Por vezes, a modificação evidencia um aspecto ou uma temática já tratada pela comissão. Em outras ocasiões, incorpora ou exclui competências designadas às comissões através do Regimento Interno. Isso sugere um esforço dos atores em tornar mais precisas e mais bem delimitadas as atividades e funções desempenhadas pelas comissões. Além disso, indica que os partidos e deputados colocam em evidência, através das comissões, tipos específicos de política pública, demonstrando uma preocupação destacada em certa temática, ao fazê-lo.

Exemplo disso é encontrado no PRC 241/2014, que inclui o tema de "Serviços" na Comissão até então chamada de Desenvolvimento Econômico, Indústria e Comércio. Nesta alteração, é patente a preocupação em se destacar o setor de serviços que, principalmente, recentemente, tem estado em destaque na discussão sobre desenvolvimento econômico no Brasil. ${ }^{7}$ Nesse sentido, esta PRC demonstra que alterações de denominação das comissões tendem a ser mais importante do que inicialmente se imaginou, pois pode demonstrar um ganho de relevância e uma busca por expertise por alguma jurisdição que, até então, vinha merecendo menos destaque.

\footnotetext{
${ }^{7}$ Segundo o Instituto Brasileiro de Geografia e Estatística (IBGE), o setor de serviços vem, nas últimas décadas, participando cada vez mais da produção econômica do país. Disponível em: https://brasilemsintese.ibge.gov.br/servicos.html. Acesso em: 16/09/2019.
} 
VASQUEZ, Vitor; FREITAS, Géssica de. Mudanças institucionais e suas consequências: uma análise do sistema de comissões brasileiro. Caos - Revista Eletrônica de Ciências Sociais, João Pessoa, n. 23, p 36-55, jul./dez. 2019. Disponível em: https://periodicos.ufpb.br/ojs2/index.php/caos/index.

O segundo aspecto que analisamos foi a mudança no número de comissões que integram o sistema. Para investigar o efeito dos PRCs que alteraram o total de comissões, elaboramos o gráfico 1, que elenca, ano a ano, o total de comissões permanentes na Câmara dos Deputados. O intuito foi observar em que medida o padrão destas alterações se mantém ou se modifica com o passar dos anos, buscando apreender se existe uma estratégia homogênea dos partidos e deputados em expandir ou reduzir o sistema, ou se isto varia ao longo do tempo. Os resultados estão expostos a seguir.

Gráfico 1: Número de comissões permanentes, 1989-2018

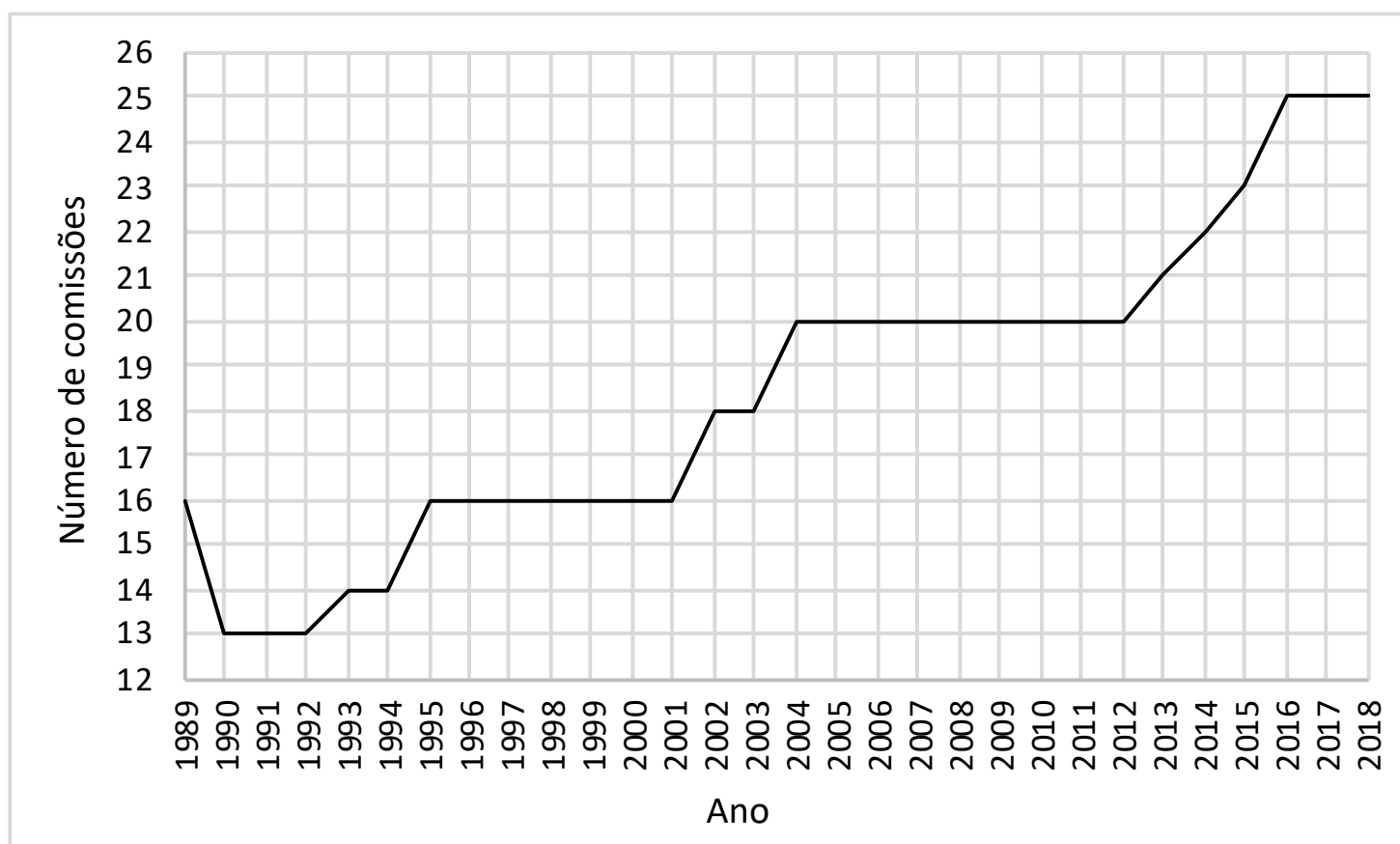

Fonte: Elaboração própria

Como pode ser observado, o total de comissões varia durante o tempo, o que demonstra que esta alteração institucional ocorre com frequência no sistema brasileiro. Mais importante, o gráfico evidencia que as alterações acontecem, em geral, via incrementos. Isto pode indicar uma constante ampliação no número de temáticas políticas representadas no sistema, além de um aumento gradativo de incentivo à especialização destes órgãos, pois a maioria dos PRCs desta categoria diz respeito a desmembramento ou criação de competência. As próprias justificativas apresentas por estes PRCs apontam para um melhor aparelhamento das comissões, dando-lhes melhores condições de formular políticas públicas. 
VASQUEZ, Vitor; FREITAS, Géssica de. Mudanças institucionais e suas consequências: uma análise do sistema de comissões brasileiro. Caos - Revista Eletrônica de Ciências Sociais, João Pessoa, n. 23, p 36-55, jul./dez. 2019. Disponível em: https://periodicos.ufpb.br/ojs2/index.php/caos/index.

Interessante notar que grande parte destes PRCs é aprovada no mesmo ano em que é proposta, provocando efeito imediato ou na próxima sessão legislativa. Exceções à regra são os PRCs 21/1995, 27/1999 e 8/2007. O primeiro projeto cria a Comissão da Amazônia e do Desenvolvimento Regional. No entanto, só entra em vigor a partir de 1997. O segundo prevê a Comissão de Segurança Pública, Combate ao Crime Organizado, Violência e Narcotráfico. Este, apesar de proposto em 1999, só tem efeito a partir de 2003. O terceiro estabelece a Comissão dos Direitos da Mulher e a da Defesa dos Direitos da Pessoa Idosa. Porém, só passa a valer a partir de 2016.

Por fim, destacamos a maior relevância das comissões mais antigas do sistema. Desde 1991, existe uma categoria específica de comissão permanente: comissão cumulativa. Segundo o RICD, cada deputado deve ser titular de somente uma comissão, com exceção das comissões cumulativas. À época, somente a Comissão de Defesa Nacional possuía este status. Atualmente, 11 comissões são cumulativas, ${ }^{8}$ sendo que a grande maioria não existia no começo do sistema de comissões brasileiro. Dado que as outras comissões - aquelas que tendem a ser as mais antigas do sistema - requerem exclusividade entre si, pode-se inferir que as cumulativas - em geral, mais novas - tendem a ser menos relevantes se comparadas às demais. Se for este o caso, devemos esperar que estas comissões sejam menos desejadas pelos partidos e deputados. Isto pode ser conferido ao se analisar a quantidade de membros que tende a ocupar as comissões cumulativas. Para tanto, elaboramos o gráfico 2, através do qual realizamos uma exploração geral do número de membros das comissões ao longo dos anos. ${ }^{9}$

Os resultados apresentados nesse gráfico permitem observar uma alta variância na mediana do número de membros de cada comissão durante o período. Esta variação, ao

\footnotetext{
${ }^{8}$ Comissões de Legislação Participativa, de Segurança Pública e Combate ao Crime Organizado, de Cultura, de Defesa dos Direitos das Pessoas com Deficiência, de Direitos Humanos e Minorias, do Esporte, de Meio Ambiente e Desenvolvimento Sustentável, de Relações Exteriores e de Defesa Nacional, de Turismo, de Integração Nacional, Desenvolvimento Regional e da Amazônia, de Defesa dos Direitos da Mulher e de Defesa dos Direitos da Pessoa Idosa.

${ }^{9}$ Para o cálculo do total de membros de cada comissão, mobilizamos duas fontes diferentes. De 1989 a 1994, utilizamos os atos da Mesa, no início de cada sessão legislativa, que definem a proporção partidária e a quantidade de membros de cada comissão. De 1995 a 2018, no entanto, utilizamos informações precisas de data de entrada e saída dos membros titulares. A partir disso, calculamos a quantidade mensal e, posteriormente, a média anual de membros em cada comissão. Este procedimento foi adotado apenas no período para o qual o Centro de Documentação e Informação (Cedi) da Coordenação de Relacionamento, Pesquisa e Informação (Corpi) da Câmara dos Deputados disponibilizou os dados.
} 
VASQUEZ, Vitor; FREITAS, Géssica de. Mudanças institucionais e suas consequências: uma análise do sistema de comissões brasileiro. Caos - Revista Eletrônica de Ciências Sociais, João Pessoa, n. 23, p 36-55, jul./dez. 2019. Disponível em: https://periodicos.ufpb.br/ojs2/index.php/caos/index.

longo do tempo, ocorre de forma decrescente. Assim, ao longo dos anos, considerando a mediana, cada vez menos membros passaram a participar de cada comissão. Da mesma maneira, há uma queda no valor de terceiro quartil, principalmente entre 2004 e 2014. Cabe destacar também que, em metade dos anos analisados, a Comissão de Constituição e Justiça e de Cidadania (CCJC) foi um outlier superior, ratificando o argumento de trabalhos que apontam esta como uma comissão chave para o sistema (INÁCIO; REZENDE, 2015; SANTOS, 2002).

Gráfico 2: Box-plot do número de membros por comissão, 1989-2018

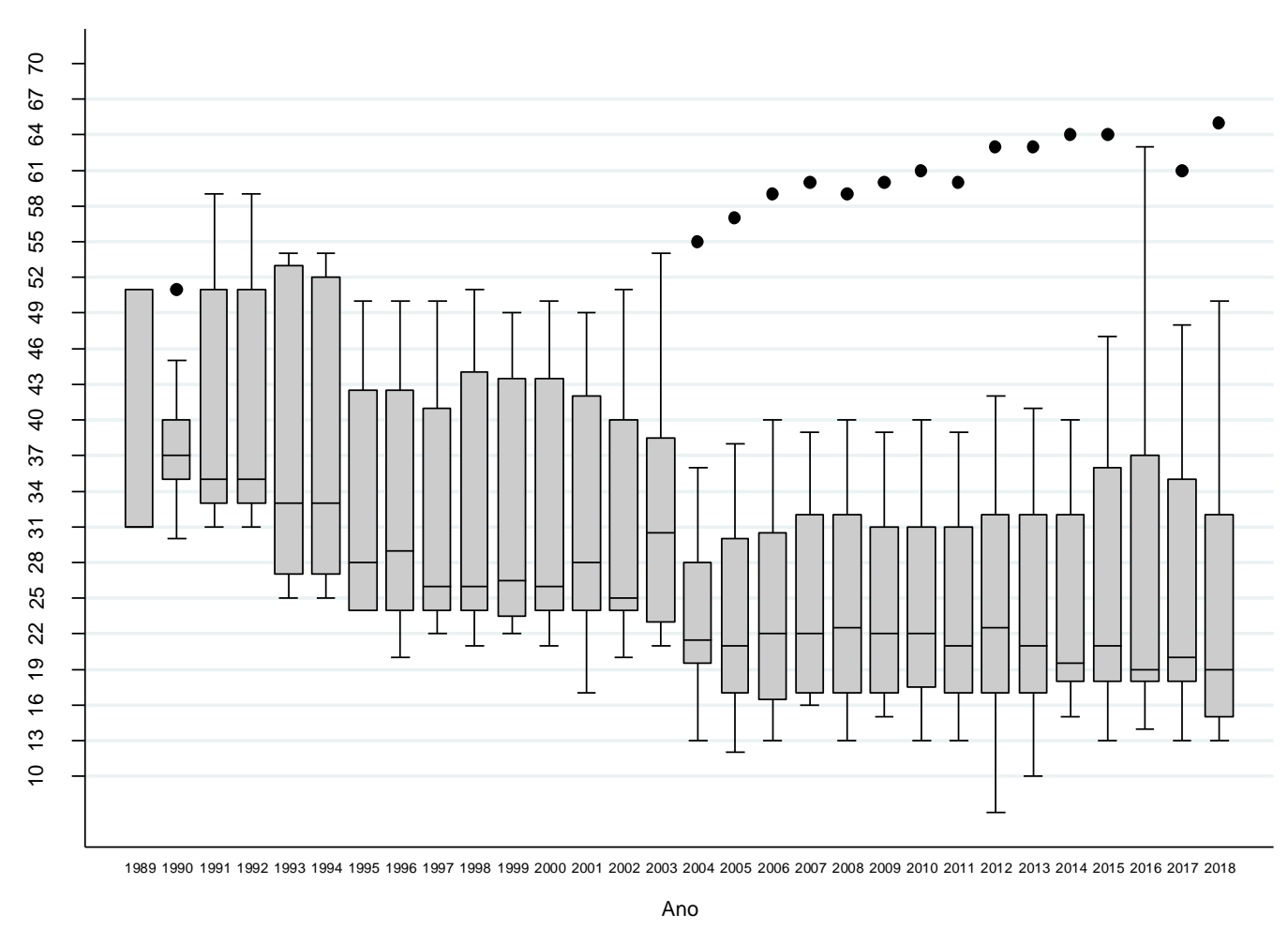

Fonte: Elaboração própria

Interessante notar que o decréscimo nas medianas ocorre em paralelo a um importante incremento no número de comissões. Assim, ao passo que no gráfico 1 observamos um aumento na quantidade destes órgãos no sistema, o gráfico 2 demonstra que, quase paralelamente, há uma redução no número de membros médio das comissões. No entanto, este decréscimo ocorre em função quase que essencialmente das novas comissões. As mais antigas, por outro lado, até aumentam o número de membros nos 
últimos anos, como pode ser observado pela retomada dos valores de terceiro quartil a partir de 2015, bem como nos valores de máximo.

Isto indica que somente a criação, ou desmembramento de novas temáticas, não garante que estas serão priorizadas por partidos e deputados, embora conforme um importante indicativo, dada a regra da maioria, e incentivo, em função dos recursos destinados às comissões, para que isso aconteça. Porém, além disso, é preciso que se gere outros impulsos e constrangimentos para que os atores políticos do Legislativo se dediquem a essas jurisdições. Parte disso é promovida pelo RICD, através da exigência de que um mínimo da Câmara componha esses órgãos. Por outro lado, um maior ganho de relevância das comissões mais recentes demanda a institucionalização de suas áreas, algo obtido também pelo tempo de existência, característica que favorece as comissões mais longevas em termos de atratividade. Para corroborar essa relevância das comissões mais antigas, elaboramos o gráfico 3. Nele, distribuímos a idade das comissões em função do número médio de membros que cada comissão teve ao longo de sua existência.

Gráfico 3: Idade das comissões vs. número médio de membros titulares, 1989-2018

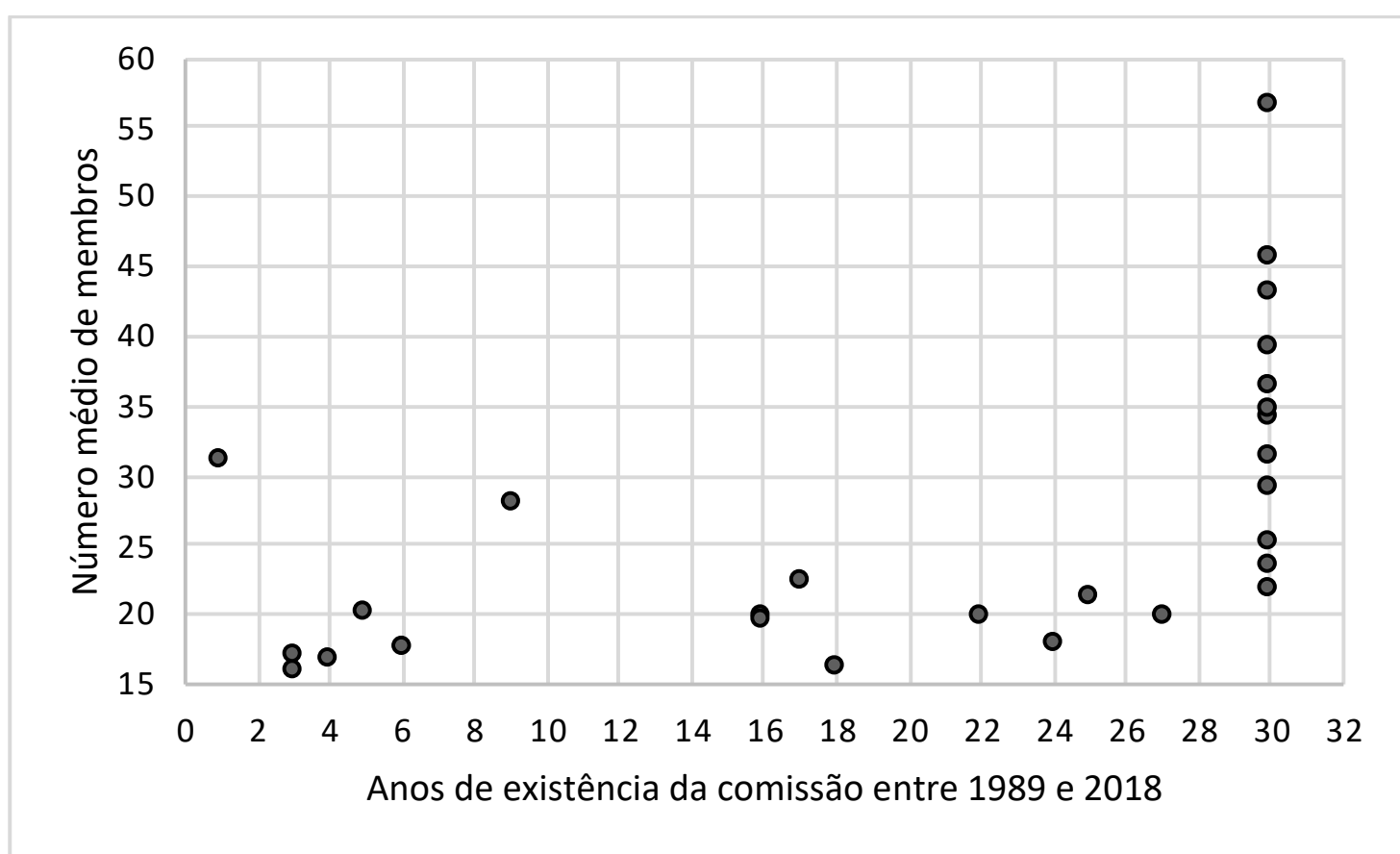

Fonte: Elaboração própria 
VASQUEZ, Vitor; FREITAS, Géssica de. Mudanças institucionais e suas consequências: uma análise do sistema de comissões brasileiro. Caos - Revista Eletrônica de Ciências Sociais, João Pessoa, n. 23, p 36-55, jul./dez. 2019. Disponível em: https://periodicos.ufpb.br/ojs2/index.php/caos/index.

Através do gráfico, é nítido como as comissões mais antigas do sistema são aquelas que, em média, mais membros possuem. Dado os limites de participação estabelecidos pelo próprio RICD - número máximo de membros e comissões exclusivas -, isto sugere uma maior relevância dessas comissões. Cabe destacar que duas comissões com poucos anos de existência apresentaram uma média próxima a 30 membros, sendo menos desproporcional às quais possuem maior idade. No entanto, essas comissões existiram nos primeiros anos do sistema, ${ }^{10}$ quando este ainda era composto por menos órgãos. Finalmente, salientamos que dentre as comissões cumulativas, somente a de Relações Exteriores e Defesa Nacional tem média superior a 30 membros (36). Não por acaso, esta é a única comissão atualmente cumulativa existente desde 1989. Salvo esta exceção, nenhuma outra comissão deste tipo possui média de deputados titulares superior a 23. Isto ratifica o que fora observado quando analisamos o número de comissões do sistema, isto é, que as comissões mais jovens tendem a ser as menos relevantes. Afinal, além de mais recentes e, portanto, menos institucionalizadas, elas, em geral, são cumulativas e possuem uma menor quantidade de membros titulares.

Finalmente, a última categoria de alteração investigada é a que versa sobre procedimentos internos das comissões. Através da análise dos PRCs que se enquadram nessa categoria, é possível observar, em um momento inicial e mais próximo ao estabelecimento do Regimento Interno de 1989, um movimento de definição das comissões temáticas, de seus trabalhos e da forma como estes se seguirão. Nessa direção, o PRC 55/1989 foi basilar para o sistema, definindo os tipos de projetos que teriam prioridade nas comissões, e que cada comissão contaria com um presidente e três vicepresidentes.

Essas primeiras alterações procedimentais demonstram uma preocupação dos atores com questões práticas, como a definição de prazos exequíveis para o escrutínio das proposições e soluções que garantam o seguimento das apreciações, caso esses prazos não sejam cumpridos. Aqui, destaca-se a PRC 200/1994, que definiu prazos antes inexistentes e ampliou prazos já existentes, visando agilizar os trabalhos das comissões.

\footnotetext{
${ }^{10}$ Estas comissões são as seguintes: de Serviço Público, que foi incorporada à de Trabalho já em 1990 e a de Defesa Nacional, anexada à de Relações Exteriores em 1997.
} 
Além disso, esse projeto institui maior poder aos presidentes das comissões, ao definir que estes podem exercer o papel de relator, em caso de omissões, findado o prazo estabelecido. Paralelamente, ampliou o poder de agenda da própria comissão enquanto órgão coletivo, estabelecendo que ela pode, mediante requerimento de um terço de seus membros, aprovado pela maioria, incluir matéria na Ordem do Dia do órgão.

Quanto ao PRC 134/2016, último transformado em norma jurídica desta categoria, observa-se um esforço para manter a ordem no processo de votação e dos procedimentos internos como um todo, tornando o processo deliberativo mais eficiente. Tal tentativa é feita através de um dispositivo acrescentado ao RICD que regulamenta a votações dos suplentes das comissões, em caso de ausência dos titulares.

\section{Considerações Finais}

Nosso artigo demonstrou que os PRCs analisados possuem consequências importantes para o sistema de comissões. Isto ocorre mesmo com as alterações que poderiam ser pensadas como não tão relevantes, por versarem somente sobre a denominação dos órgãos. Neste caso, evidenciamos que estas transformações expressam preocupação dos atores com certos tipos de temas específicos.

Quanto ao funcionamento do sistema, apontamos que, mais inicialmente, próximo ao estabelecimento do primeiro Regimento Interno, pós CF-88, foram aprovados PRCs mais basilares para a organização dos trabalhos nas comissões. Desse modo, foram definidas questões práticas, como a definição de prazos exequíveis para o escrutínio das proposições. Com o passar do tempo e a institucionalização dos procedimentos, os PRCs passaram a ampliar o poder de agenda das comissões enquanto órgãos coletivos, e a tentar tornar o processo deliberativo mais eficiente.

Outro ponto evidenciado por nosso artigo é que o número de comissões aumentou no decorrer do período analisado, ao passo que o número médio de membros em cada comissão caiu. Parte disso ocorre, porque o número de parlamentares da Câmara dos Deputados permanece fixo em 513. Assim, um aumento do número de comissões, com o mesmo contingente de parlamentares, logicamente levaria à diminuição da quantidade de parlamentares por comissão. Contudo, mostramos que existem comissões que vão na 
contramão dessa lógica, mantendo, ou mesmo aumentando, a quantidade de deputados. Essas comissões são, geralmente, as mais antigas do sistema. Isso sugere que, apesar da importância de se criar novas comissões do ponto de vista da especialização do sistema, as jurisdições mais recentes demandarão tempo para se institucionalizar, quando comparadas às mais antigas.

Nossos resultados demonstram a importância em se realizar uma análise longitudinal do sistema de comissões brasileiro. Ao considerá-lo, desde a gestação pós redemocratização até os dias presentes, através das mudanças institucionais promovidas pelos partidos e deputados, oferecemos um desenho acurado de sua transformação até o formato atual, corroborando o argumento da literatura que vem comprovando a importância das comissões no processo legislativo (FREITAS, 2016; INÁCIO; REZENDE, 2015; SANTOS; ALMEIDA, 2011). Uma vez que seus membros reúnem maioria, via aprovação de PRCs, para fortalecer o sistema de comissões, pode-se inferir que esses atores consideram esse espaço como um importante lócus de deliberação.

Finalmente, mas não menos importante, cabe destacar que este artigo abre uma frente de pesquisa. Afinal, dado que os atores da Câmara buscaram aprimorar e fortalecer o sistema de comissões ao longo do tempo, é preciso investigar o impacto destas modificações institucionais nas atividades desenvolvidas no interior das comissões. Nesse sentido, é necessário investigar e comparar, ao longo do tempo, padrões em atividades centrais como escrutínio de projetos, para ratificar se, de fato, tais alterações fortaleceram o sistema. Nossa hipótese é que, dado o esforço de partidos e deputados em aprimorar o sistema de comissões, este passou a ter um papel cada vez mais relevante no processo legislativo brasileiro. Isto é, o gradativo aumento no número de comissões e as mudanças procedimentais que visaram maior eficiência do sistema tenderam a tornar o papel destes órgãos mais relevantes no processo legislativo. Isto poderia ser testado através de investigações em torno do volume de proposições analisadas e aprovadas internamente às comissões; do tempo médio de tramitação das matérias; e de alteração nos projetos escrutinizados e, até mesmo, de uso do poder terminativo. 
VASQUEZ, Vitor; FREITAS, Géssica de. Mudanças institucionais e suas consequências: uma análise do sistema de comissões brasileiro. Caos - Revista Eletrônica de Ciências Sociais, João Pessoa, n. 23, p 36-55, jul./dez. 2019. Disponível em: https://periodicos.ufpb.br/ojs2/index.php/caos/index.

Referências

BINDER, S. A. Partisanship and procedural choice: institutional change in the early congress, 1789-1823. The Journal of Politics, Los Angeles, v. 57, n. 4, p. 1093-1118, 1995.

FIGUEIREDO, A.; LIMONGI, F. Executivo e legislativo na nova ordem constitucional. 2. ed. Rio de Janeiro: Editora FGV, 2001.

FREITAS, A. O presidencialismo da coalizão. Rio de Janeiro: Fundação Konrad Adenauer, 2016.

GOMES, S. O impacto das regras de organização do processo legislativo no comportamento dos parlamentares: um estudo de caso da Assembleia Nacional Constituinte (1987-1988). Dados, Rio de Janeiro, v. 49, n. 1, p. 193-224, 2006. Disponível em: http://www.scielo.br/scielo.php?script=sci_arttext\&pid=S0011-52582 006000100008. Acesso em: 20/12/2019.

HUBER, J. D.; MARTINEZ-GALLARDO, C. Replacing cabinet ministers: patterns of ministerial stability in parliamentary democracies. American Political Science Review, New York, v. 102, n. 2, p. 169-180, 2008.

IMMERGUT, E. Health politics: interests and institutions in Western Europe. Cambridge: Cambridge University Press, 1992.

INÁCIO, M.; REZENDE, D. Partidos legislativos e governo de coalizão: controle horizontal das políticas públicas. Opinião Pública, Campinas, v. 21, n. 2, p. 296-335, ago. 2015.

KREHBIEL, K. Information and legislative organization. Michigan: University of Michigan Press, 1992.

MARTIN, L.; VANBERG, G. Parliaments and coalitions: the role of legislative institutions in multiparty governance. New York: Oxford University Press, 2013.

MARTIN, S. Committees. In: MARTIN, S.; SAALFELD, T.; STRØM, K. (Eds.). The Oxford handbook of legislative studies. Oxford: Oxford University Press, 2014, p. 35270 .

MATTSON, I.; STRØM, K. Parliamentary committees. In: DORING, H. (Ed.). Parliaments and majority rule in Western Europe. Frankfurt, New York: Palgrave Macmillan, 1995, p. 249-307.

MEDEIROS, D. B. Organizando maiorias, agregando preferências: a Assembleia Nacional Constituinte de 1987-88. São Paulo: Universidade de São Paulo, 2013.

NORTH, D. C. Institutions, institutional change and economic performance. Cambridge: Cambridge University Press, 1990.

PRZEWORSKI, A. Institutions matter? Government and Opposition, Cambridge, v. 
39, n. 4, p. 527-540, 2004.

SANTOS, F. Partidos e comissões no presidencialismo de coalizão. Dados, Rio de Janeiro, v. 45, n. 2, p. 237-264, 2002.

SANTOS, F.; ALMEIDA, A. Fundamentos informacionais do presidencialismo de coalizão. Curitiba: Editora Appris, 2011.

STRØM, K. Minority government and majority rule. Cambridge: Cambridge University Press, 1990.

Recebido em: 20/09/2019.

Aceito em: 06/11/2019. 